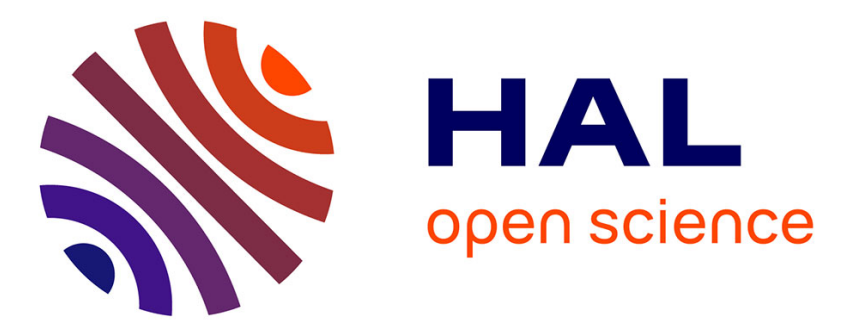

\title{
Working memory function is linked to trauma exposure, independently of post-traumatic stress disorder symptoms
}

Isabelle Blanchette, Serge Caparos

\section{- To cite this version:}

Isabelle Blanchette, Serge Caparos. Working memory function is linked to trauma exposure, independently of post-traumatic stress disorder symptoms. Cognitive Neuropsychiatry, 2016, 21 (6), pp.494 509. 10.1080/13546805.2016.1236015 . hal-01760915

\section{HAL Id: hal-01760915 https://hal.science/hal-01760915}

Submitted on 11 Apr 2018

HAL is a multi-disciplinary open access archive for the deposit and dissemination of scientific research documents, whether they are published or not. The documents may come from teaching and research institutions in France or abroad, or from public or private research centers.
L'archive ouverte pluridisciplinaire HAL, est destinée au dépôt et à la diffusion de documents scientifiques de niveau recherche, publiés ou non, émanant des établissements d'enseignement et de recherche français ou étrangers, des laboratoires publics ou privés.

\section{(이)( $)$}

Distributed under a Creative Commons Attribution - NonCommercial - NoDerivatives| 4.0 


\title{
Working memory function is linked to trauma exposure, independently of post-traumatic stress disorder symptoms
}

\author{
Isabelle Blanchette ${ }^{a}$ and Serge Caparos ${ }^{b}$ \\ áépartement de Psychologie, Université du Québec à Trois-Rivières, Trois-Rivières, QC, Canada: \\ bépartement de Psychologie, Université de Nimes, Nìmes, France
}

\begin{abstract}
introduction: The purpose of the study was to examine how working memory (WM) may be related to exposure to potentially traumatic events and symptoms of post-zraumatic stress disorder (PTSD).

Method: In four studies, we measured WM function using adaptations of the running span and the reading span tasks. We compared the performance of women reporting experiences of sexual abuse to control participants (total $n=144$ controls and 84 victims). We measured severity of the sexual abuse experiences as well as exposure to general life stress.

Results: In all studies, trauma exposed participants showed significantly lower WM function compared to control perticipants. In addition to traditional null hypothesis testing we used a minimeta analysis to estimate the combined estimated effect size of this difference, which was in the moderate range $(d=0,43$ with $0.15-0.7095 \%$ confidence interval). Regression equations showed that PTSD symptoms did not mediate the retationship between trauma exposure and WM function.

Conclusions: Our results show that trauma exposure per se can be associated with important cognitive correlates even in individuals who do not develop psychopathological reactions.
\end{abstract}

\section{KEYwORDS}

Trauma; working mernory: sexual abuse; executive function; PTSD

A majority of individuals will experience at least one potentially traumatic event (PTE) during their lifetime, and following this, most will not develop psychopathological reactions such as post-traumatic stress disorder (PTSD) (Resnick, Kilpatrick, Dansky, Saunders, \& Best, 1993). The impact of PTEs on individuals who do not develop PTSD is not well understood. In particular, though important cognitive correlates of PTSD have been identified (Tapia, Clarys, El-Hage, \& Isingrini, 2007), it is not clear if and how exposure to PTEs can in itself be related to cognitive functioning. In this paper, we report studies probing working memory (WM) in participants exposed to trauma (sexual abuse) and in non-exposed control participants.

A traumatic event is an event that is shocking and emotionally overwhelming that can involve actual or threatened death, serious injury or threat to physical integrity. A large portion of the population will be exposed to at least one PTE in their life time; estimates range from $60 \%$ to $89 \%$ (Breslau, 2009; Resnick at al, 1993). The majority of individuals exposed to PTE do not develop PTSD (lifetime prevalence of PTSD is estinated between 
$7 \%$ and $12 \%$; Breslau, 2009; Resnick et al., 1993). Whereas the health correlates of PTE exposure have been examined (e.g., links between PTE and depression, Suliman et al., 2009 , or general physical health), their potential cognitive correlates have not received much interest, despite increasing evidence that PTSD following PTE exposure is linked with cognitive functioning.

PTSD is associated with broad nearocognitive characteristics including alterations to verbal learning, verbal memory, attention and speed of information processing (Scott et al., 2015). In particular, a number of studies have documented lower episodic memory function in individuals suffering from PTSD compared to controls (see Isaac, Cushway, \& Jones, 2006 for a review). A snaller number of studies have documented alterations of WM associated with PTSD (Schweizer \&.Dalgleish, 2011; Vasterling, Brailey, Constans, \& Sutker, 1998). In one experiment using an auditory n-back task (Galletly, Clark, McFarlane, \& Weber, 2001), participants with PTSD were found to be less accurate than control participants matched on age and education. Other studies have documented similar differences in accuracy between PTSD-suffering and control participants using various WM tasks (Bomyea, Risbrough, \& Lang, 2012; Moores et al., 2008; Morey et al, 2009). Effect sizes of the difference between groups in these studies are usually large ( $d$ values between 0.96 and 1.5). In some studies, differences between groups $(d=0.87-1.38)$ were found in reaction times rather than in accuracy (Clark et al,, 2003; Weber et al., 2005).

The findings of these studies seem to point to impairment in WM function related to PSTD. However, resalts of the broader literature are equivocal. First, a number of studies have failed to find significant differences between PTSD-sulfering and control participants, sometimes using similar WM tasks (LaGarde, Doyon, \& Brunet, 2010; Neylan et al., 2004; Schweizer \& Dalgleish, 2011). Second, there are inconsistencies in that the same tasks sometimes produce differences in reaction times and not accuracy, and sometimes in accuracy but not reaction times (Galletly et al., 2001; Moores et al., 2008). Because generic processing speed deficits have been documented in PTSD (Nelson, Yoash-Gantz, Pickett, \& Campbeil, 2009), one can question whether there is a specific effect related to WM. Finally, the question of causality is one of the most difficult to settle. Lower cognitive abilities (lower IQ) is a risk factor for developing PTSD (Macklin et al., 1998). A large portion of the variance in fluid intelligence is associated with WM function (Engle, Tuholski, Laughlin, \& Conway, 1999). Thus, it is not clear whether PTSD leads to WM impairments or if WM impairments predispose to or precipitate the development or PTSD.

Moreover, and central to the current investigation, it is not yet clear whether the differences documented in WM function are actually related to PTSD or to trauma exposure. In the literature on WM and PTSD, participants suffering from PTSD are most often compared to control participants who have not been exposed to trauma. Only a few studies use both a non-exposed non-PTSD and an exposed non-PTSD group for comparison (e.g., LaGarde et al., 2010). Because most studies compare groups that vary on both PTSD status and PTE exposure, it is difficult to determine if differences in WM are related to PTSD symptoms or to trauma expostre.

There are reasons to suspect that, independendly of PTSD, trauma exposure itself may be linked with decreased WM funclion. Experimental inductions of stress (Luethi, Meier, \& Sandi, 2008; Schoofs, Preuss, \& Wolf, 2008) and naturally occurring acute stressors (eg., military training; Taverniers, Van Ruysseveldt, Smeets, \& von Grumbkow, 2010) can cause impairments in WM function. Laboratory-created emotional events have also been shown 
to alter WM function. In a series of studies, Curci, Lanciano, Soleti, and Rimé (2013) and Curci, Soleti, Lanciano, Doria, and Riné (2015) exposed participants to emotional videos or text (for instance, describing an episode of torture) or neutral equivalents. They tested WM function before and after this emotional event. In the neutral control condition, WM performance improved over the two tests. This was not the case when an emotional event had been experienced, especially when the WM task was verbal in nature. This negative impact of emotion exposture on WM seemed to be particularly related to the level of unintended thoughts related to the emotional event. These thoughts may take up WM capacity, which would decrease task performance. This would be consistent with theoretical and neurofunctional models of emotion-cognition interactions, for instance that of Pessoa (2005, 2009). This model suggests that the amygdala acts as a significance detector. Emotional events are flagged, because of their significance; this results in an increased representation in sensory areas (e.g., visual cortex) as well as prioritised deployment of executive resources. The anygdala relays information concerning emotional value to the anterior cingulate cortex (ACC) which integrates it with other information, prioritises it, and relays it to prefrontal structures. In partictilar, there are important links between the ACC and the dorsolateral prefrontal cortex, responsible for executive functions, including WM updating and inhibition. This model explains why emotional stimuli, including unintended thoughts about emotional experiences, may disrupt WM function.

Experimental studies have established that enotional events can cause decrements in WM function, and have started to examine possible mechanisms for this effect. However, these studies offer only a very partial andlogy to trauma. They examine relatively mild forms of emotional events and probe very short-term effects on cognitive function. Other studies have documented an association between real-life stress exposure and long-term cognitive function. The number of important stressful events that participants report being exposed to during their lifetime appears to be negatively linked to WM performance (Klein \& Boals, 2001; Stawski, Sliwinski, \& Smyth, 2006). Further, there is a relationship between the amount of daily stress reported and concurrent WM accuracy (Stawski, et al., 2006) and reaction time (Sliwinski, Snylh, Hofer, \& Stawski, 2006), in an n-back lask. However, because most of these studies do not include a measure of PTSD symploms, it is possible that the observed link between life stress and WM function may be explained by PTSD symptoms.

Altogether the weight of the evidence indicates that (1) there is a link between induced stress or exposure to an emotional event and short-term negative effects on WM, (2) there is a possible link between PTSD and long-term effects on WM and (3) there might be a link between life stress and long-term WM function. Our interest lies in determining whether exposure to PTEs may in itself be related to long-term WM function, independently of PTSD, or instead if PTSD symptoms necessarily mediate the effect of PTE on WM. Whereas exposure to intense stressors is a precondition for PTSD, the two also have unique variance; an important number of individuals will not develop PTSD despite high traumatic exposure. WM function might be directly associated with exposure to PTE, or to psychopathological reactions to PTE, or to both.

\section{Overview of studies}

In four studies, we examined the association between PTE exposure, PTSD symptoms and WM function. We used an approach where we compared two groups of participants $\mathrm{s}_{\text {, }}$ one 
exposed and one non-exposed to a common potential trauma: sexual abuse. We only recruiled women as the prevalence of sexual abuse is higher in this group (Gouvernement du Québec, 2014). The two groups were matched for age, gender and education. In addition, we measured self-reported life stress and PTSD symptoms. In three studies, we measured WM function using a running span task (Pollack, Johnson, \& Knaff, 1959), in a fourth one we used the reading span task (Unsworth, Heitz, Schrock, \& Engle, 2005), Both tasks are primarily verbal in nature. We report the methodology for the four studies together and identify distinguishing features of each. We focus our analysis on the effect size of the difference between the groups across studies, rather than null hypothesis testing, consistent with current thinking and recommendations from an important number of sources (Cumming, 2014; Miles \& Field, 2007; Trafimow \& Marks, 2015).

\section{Method}

\section{Participants}

Participants were recruited from the student and staff community at the Universite du Québec à Trois-Rivières (UQTR) (Québec, Canada), as well as in the local community, between 2010 and 2013. We advertised the studies as exploring the link between sexual abuse and cognitive function in women. Inclusion criteria were (1) to be aged 18 years or older, (2) to be able to speak and understand French and (3) to be a woman. Exclusion criteria were (1) to have a diagnosis of psychotic disorder, (2) to suffer from a neurological disorder or have suffered a traumatic brain injury causing a loss of consciousness of more than 10 minutes, (3) to have a substance abuse problem, (4) to have a diagnosis of Attention Deficit Disorder with or without hyperactivity, (5) to have a learning disability or (6) to present symptoms of depression more severe than symptoms of PTSD (Study 4 only). PTSD was neither an exclusion nor an inclusion criterion.

Assignment to the victim/control group was based on answers to the Early Trauma Inventory-Self Report (ETT-SR) sexual events (see later). Participants who endorsed any of the five items that meet the legal definition of sexual abuse ("aggression sexuelle", Gouvernement du Québec, 2014) were inciuded in the exposed group.

Number, age and education level of participants in the victim and control groups int each study can be found in Table 1. Level of education could be indicated as completed primary (1), secondary (2), college (3), undergraduate university (4) or post-graduate

Table 1. Description of sample characteristics.

\begin{tabular}{|c|c|c|c|c|c|c|}
\hline & \multicolumn{3}{|c|}{$\begin{array}{c}\text { Age } \\
\text { Average (SD) }\end{array}$} & \multicolumn{3}{|c|}{$\begin{array}{c}\text { Education } \\
\text { Percentage college/university eduration }\end{array}$} \\
\hline & Victims & Controls & t Walue & Victirns & Controls & \\
\hline Study 1 & $\begin{array}{c}30.5(9.9) \\
n=24\end{array}$ & $\begin{array}{c}24.0(4.7) \\
n=33\end{array}$ & $3.3^{*}$ & $100 \%$ & $100 \%$ & $x^{2}(2, N=57)=0.7$ \\
\hline Study 2 & $\begin{array}{c}23.0(3.8) \\
n=22\end{array}$ & $\begin{array}{c}22.9(5.8) \\
n=37\end{array}$ & 0.7 & $97 \%$ & $95 \%$ & $x^{2}(3, N=60)=2.7$ \\
\hline Study 3 & $\begin{array}{c}21.7(3.7) \\
n=23\end{array}$ & $\begin{array}{c}21.7(2,9) \\
n=45\end{array}$ & 0.7 & $91 \%$ & $82 \%$ & $x^{2}(3, N=60)=23$ \\
\hline Study 4 & $\begin{array}{c}35.3(18.4) \\
n=15\end{array}$ & $\begin{array}{c}25.7(14.5) \\
n=29\end{array}$ & 1.9 & $93 \%$ & $100 \%$ & $X^{2}(3, N=46)=26$ \\
\hline
\end{tabular}

" Significantly different at $p<0.05$. 
university level (5). Chi squares confirmed that educational level did not differ across groups. In terms of age, it can be seen that the groups significantly differed only in Study 1 , where victims were older than controls. Where appropriate, we controlled for age in the statistical analyses.

\section{Measures}

A summary of the questionnaires used to assess the different variables in the fours studies can be found in Table 2 .

Severity of experiences of abuse. The sexual abuse section of the ETI-SR was used as an indicator of experiences of sexual abuse and their severity. We adapted the instructions to refer to lifetime occurrence rather than clildhood occurrences only. The ETI-SR includes six questions about sexual events asking participants to indicate, yes or no, whether they have had certain types of unwanted sexual experiences, including kissing, fondling, genital and oral sexual relations. We excluded one question from our analyses, as it does not unambiguously meet the legal criterion for sexual abuse in the province of Québec, mainly because it does not mention absence of consent. $A$ yes answer to any of the other five questions was used as a criterion for inclusion in the exposed group. Number of yes answers was summed to produce scores that represent an indication of severity of abuse.

General life stress. In all four studies, we used self-reported instruments to assess \$ifetime exposure to other stressful/potentially traumatic experiences. In Study 1, we used the three other sections of the ETI-SR, which meastre physical abuse, emotional abuse and general trauma. In the three other studies, we used the Life Event Inventory which is a 55-item list of generally stressful life events and PTEs. Items include events such as divorce, prolonged illness or substance abuse. In both cases scores are summed and higher scores represent more exposure.

In addition, in Study 4, we also administered the Life Event Checklist (LEC), which is part of the structured interview we used in that study: the Clinician Administered PTSD Schedule (see later). The LEC assesses the occurrence of all the P'TEs listed in the Diagnostic and Statistical Manual of Mental Disorders-IV.

PTSD symptoms. PTSD symptoms were assessed through self-report questionnaires in Studies 1-3. In Study 1, we used the Primary Care PTSD, a four-item screening instrument used in primary care (Prins et al., 2003) and the Impact of Event Scale-Version Française (IES-VF) (Brunet, St-Hilaire, Jehel, \& King, 2003). In Studies 2 and 3, participants in the exposed group completed the PTSD Checklist, Civilian Version (PCL-C) (Blanchard, Jones-Alexander, Buckley, \& Forneris, 1996).

Table 2. Summary of the measures used in the four experiments.

\begin{tabular}{lllll}
\hline & Wh & Severity of experiences of abuse & Other life stresses & PTSD symptoms \\
\hline Experiment 1 & Running span & ETI-SR - sexual abuse & ETI-SR - other & IES \\
& & & & PC-PTSD \\
Experiment 2 & Running span & EII-SR - sexual abuse & LEI & PCL-C \\
Experiment 3 & Running span & ETI-SR - sexual abuse & LEI & PCL-C \\
Experiment 4 & Reading span & ETI-SR - sexual abuse & LEI & CAPS \\
& & & LEC (fron CAPS) & \\
\hline
\end{tabular}

Notes: ET-SR, Early Trauma Ifwentory-Se:F-Report; LEI, Life Event Inventon; CAPS, Clinician Administered PTSD Schedule, PC-PTSD, Primary Care PTSD and PCL-C, Post-Iraumatic Checklist, Civilian Version. 
In Study 4, we used a French version of the well validated and broadly used Clinician Administered PTSD Scale (CAPS) (Saint-Onge, n.d.). The CAPS is a structured interview assessing the presence and severity of PSTD symptoms. The structure is based on criterion $\mathrm{B}, \mathrm{C}$ and D of the DSM-IV; re-experiencing, avoidance and hyperarousal. Each item is scored on a scale from 0 (never) to 4 (extremely).

WM assessment. In Studies 1-3, we used a running span task adapted from Vieillard and Bougeant (2005). Participants were presented with series of consonants (from four to nine consonants), without repetition. Each consonant was presented for $850 \mathrm{~ms}$ visually in the centre of the screen, with a 650 -ms interstimulus interval. The presentation of the last item of the series was indicated by a $950-\mathrm{ms}$ beep. Following this, participants had to type in the last four items of lists of four, six or eight consonants (block 1), or the last five items of lists of five, seven or nine itens (block 2). There were 12 different trials in each block. This task requires participants to update the contents of memory, because they do not know when the list will end. It therefore measures WM, rather than short-term memory. In this particular task, retaining and apdaling four items represents a lower load, whereas five items represents a higher load (Viellard \& Bougeant, 2005). The low load was presented in the first block and the high load in the second block. Before the start of each block, there were two practice trials. Accuracy was the dependent variable analysed. There was no time limit for participants to provide their response. A trial was coded as correct (1) if the participants recalled all items in the correct order, otherwise it was coded as incorrect (0). In Study 3, only the high load condition was used.

In Study 4 , we used a locally translated and adapted version of the automated reading span (Redick et al., 2012). In this task, participants perform a storage task and a processing task. They must remember a randon sequence of consonants. The presentation of these consonants is interspersed with a verbal task in which participants have to determine whether a sentence is grammatically correct or not. Participants first practiced memotising the leters ( 4 trials), then practiced the verbal task alone ( 15 trials) and then practiced 3 trials with both tasks combined. The actual experimental block comprised 15 trials, presented one at a time, with letter sets varying from 2 to 6 items to be remembered (with an equivalent number of sentences to process in between). The length of the intertrial intervals were determined by participants who pressed the space bar when they were ready to start the next trial. Again, a trial was coded as accurate if participants could recall all the letters in the correct order.

\section{Procedure}

The data reported in this paper were collected as part of a larger investigation of the cognitive correlates of trauma. Participants came for one session (Studies I-3) or two sessions (Study 4) and completed a number of other cognitive tasks in addition to the one described here, namely, a deductive reasoning task, an attentional cueing task, an attentional network task and a task assessing the interpretation of ambiguous stimuli. Because the theoretical questions addressed with these tasks are different, these data are not reported here. The tasks, including questionnaires and cognitive tasks, were presented using EPrime.

Participants first read the information shee and signed the consent form. They were informed that the study induded questions about personal, potentially difficult and 
emotional topics and that even if they agreed to participate, they could skip any question, or interrupt their participation at any time. All studies were approved by the ethics committee of UQTR.

The general procedure followed this sequence: demographic questions, cognitive tasks (always in the same order, WM task was the second to last task) and then questionnaires. Participation ended with a debriefing and referral to appropriate services if necessary. This general procedure differed only in Study 4, for which participants came to the laboratory on two different occasions. The first session consisted in administering the CAPS and filling out the self-reported questionnaires. Participants completed the cognitive tasks in a second session.

\section{Data analysis}

Our main metric of interest is the effect size of the difference between WM accuracy in the exposed and control groups, which we quantify using Cohen's $d$. The data are combined in a mini-meta analysis used to compute the confidence interval (CI) of the estimated difference in accuracy between groups (Cumming, 2014). Although we report significance testing of the difference between the groups, we focus on effect sizes and CIs of the combined studies following recommendations of best statistical practice emanating from different sources, including the Association for Psychological Science and the American Psychological Association (Cumming, 2014; Trafimow \& Marks, 2015). There are important, insoluble problems with null hypothesis testing. Focusing on estimates of effect size and combining results across studies has been recommended as a key to improving replicability in science and more meaningful data analysis.

The standardised scores on all independent and dependent variables are also combined across studies to examine the interrelations between variables. Regression models are used to determine if PTE exposure, severity of reported experiences and general life stress are related to WM function, and, importantly, if this relation is mediated by PTSD symptoms. This mediation hypothesis was tested using two methods: following the procedure described by Hayes (2013) and the Sobel test. We used the PROCESS SPSS computational tool (Hayes, 2012) to calculate the direct relation between WM performance and severity of exposure as well as the indirect relation, through PTSD symptoms. The strength of this indirect relation indicates the extent to which the link belween WM function and severity of exposure is actually related to increased PTSD symptoms.

\section{Results}

Average accuracy on the WM tasks is reported for all conditions (low, high load), groups (exposed, controls) and studies in Table 3. It can be seen that participants in the exposed group consistently presented lower WM scores compared to controls, in all conditions, in all studies. This difference between groups was tested for the average span in each study separately using one-tailed independent sample $t$-tests, as the prediction was that participants in the exposed group would show lower WM accuracy than those in the control group. The difference was significant in all cases.

More importantly, we calculated effect sizes to quantify the extent of these differences in accuracy between groups, using Cohen's $d$. Results are presented in Figure 1, with black 
Table 3. Average performance on WM tasks in the fours studies, presented by group and difficulty level (when relevant).

\begin{tabular}{|c|c|c|c|}
\hline & $\begin{array}{c}\text { Average WM accuracy } \\
\text { Mean (SD) }\end{array}$ & $\begin{array}{c}\text { Low load condition } \\
\text { Mtean (SD) }\end{array}$ & $\begin{array}{l}\text { High load condition } \\
\text { Mean (SD) }\end{array}$ \\
\hline \multicolumn{4}{|l|}{ Study 1} \\
\hline Controls & $0.41(0.17)$ & $0.55(0.20)$ & $0.28(0.21)$ \\
\hline Victims & $\begin{array}{c}0.34(0.15) \\
t(55)=1.63, p=.05\end{array}$ & $0.46(0.21)$ & $0.22(0.74)$ \\
\hline \multicolumn{4}{|l|}{ Study 2} \\
\hline Controls & $0.32(0.74)$ & $0.43(0.76)$ & $0.21(0.14)$ \\
\hline Victims & $\begin{array}{c}0.26(0.14) \\
t(57)=1.73, p=.04\end{array}$ & $0.36(0.18)$ & $0.16(0.11)$ \\
\hline \multicolumn{4}{|l|}{ Study 3} \\
\hline Controts & $0.28(0.77)$ & & $0.28(0.17)$ \\
\hline Victirns & $\begin{array}{c}0.20(0.14) \\
t(66)=1.85, p=.03\end{array}$ & & $0.20(0.14)$ \\
\hline \multicolumn{4}{|l|}{ Study 4} \\
\hline Coftrols & $0.47(0.18)$ & & \\
\hline Vktims & $\begin{array}{c}0.27(0.16) \\
t(42)=2.64, p<.01\end{array}$ & & \\
\hline
\end{tabular}

squares indicating the effect size in each study (the size of the square represents the sample size) along with $95 \%$ CIs (black lines). The estimate produced from the combined data is represented by the diamond. Overall the combined studies show a moderate effect size estimated at 0.43 (weighed by sample sizes) with a $C I$ between 0.15 and 0.70 . This shows that there is a consistent difference of moderate size in the average WM accuracy of the exposed and non-exposed groups.

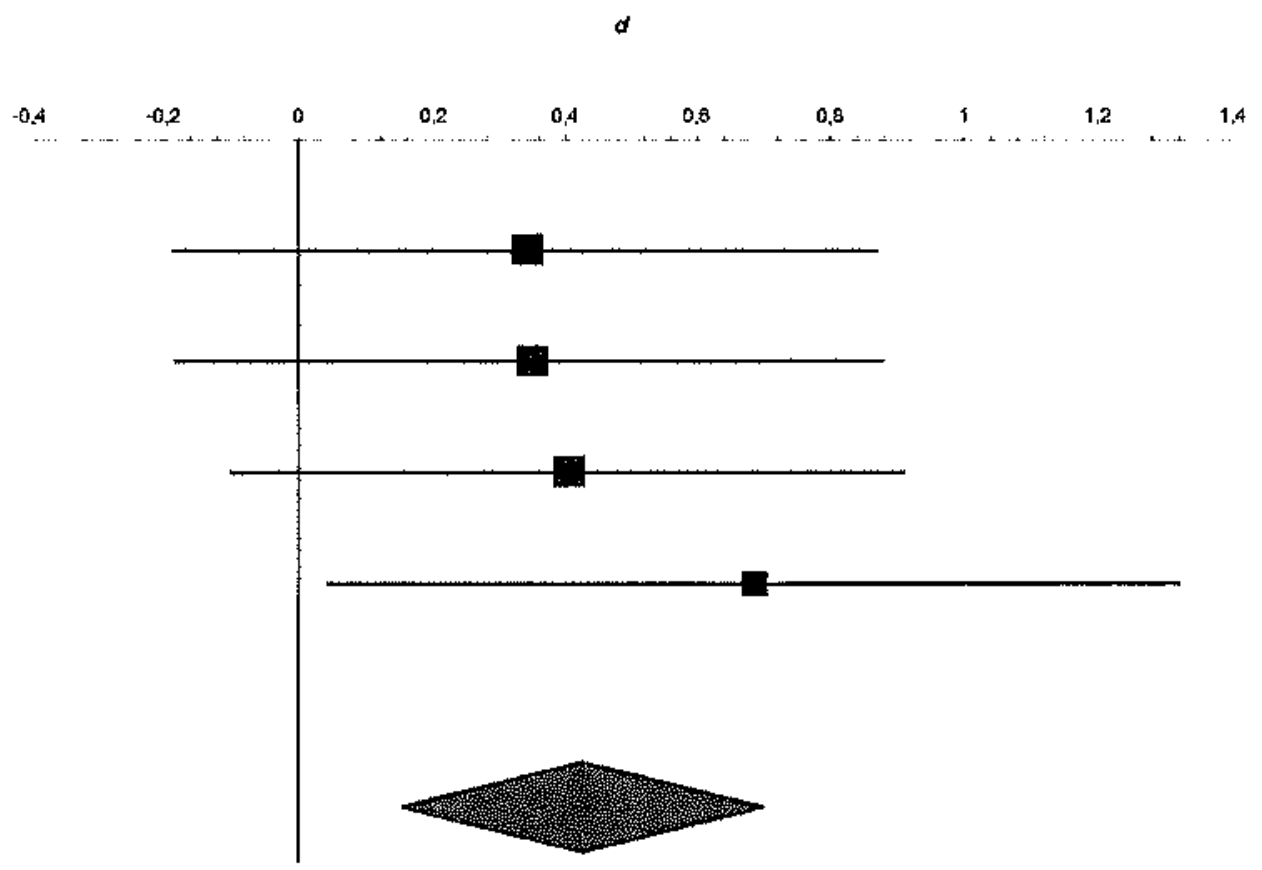

Figure 1 . Effect size of the difference in WM function between exposed and control groups in the fours studies (squares) and combined (diamond), weighed by sample size and with $95 \% \mathrm{Cls}$. 
Table 4 reports the correlations between the different variables in the combined data, using standardised scores from each study. It can be seen that WM accuracy correlated significantly with the reported severity of experiences of sexual abuse as well as with general life stress. WM accuracy did not, however, correlate with level of PTSD symptoms.' Intercorrelations between the questionnaire measures show that general life stress was positively related to experiences of sexual abuse and that level of PTSD symptoms was positively related to general life stress and to the severity of experiences of abuse, as would be expected.

We classiffed participants as PTSD or non-PTSD, using the recommended clinical cutoff scores for the respective instruments used in the different studies. The number of victims reaching this criterion was $10(41.7 \%), 5(23.8 \%), 6(26.1 \%)$ and $4(26.7 \%)$ for Studies 1 through 4 , respectively. Overall, the proportion of participants reaching the PTSD cut-off was greater in the victim group (30.1\%), compared to the control group $(4.3 \%), \chi^{2}(1, N=177)=21.5, p<.01$. We compared WM performance (using the standardised scores of accuracy) of the PTSD group $(M=0.10, \mathrm{SD}=1.07, n=28)$ and non-PTSD group $(M=-0.06, \mathrm{SD}=1.01, n=147)$. The means did not differ significantly between groups, $t(173)=0.73, p=.47, d=-0.14$.

The final step in our analyses was to investigate whether trauma and stress exposure (sexual abuse experience and general life stress) was directly related to WM accuracy or whether the relationship was mediated by PTSD symptoms. We considered exposure asing three measures: group (dummy coded as 0 for controls and 1 for victims of sexual abuse), severity of reported experiences of sexual abuse and general life stress. We first examined whether these three variables together predicted WM function, above and beyond age which was enlered in a first step. The model was significant, $F$ $(4,222)=6.85, p<.01, R^{2}=.11$. More importantly, the second step (including the exposure variables after age) provided incremental significance, $F(3,222)=7.16, p<.01$, incremental $R^{2}=.09$. Group $(\beta=-.25, p=.02)$ and general life stress $(\beta=-.19, p<.01)$ were the more important predictors, compared to severity $(\beta=.11, p=.31)$. Following this, we examined whether this relationship between stress exposure and WM was mediated by PTSD symptoms. We used the procedure described by Hayes (2013) to test for mediation. This procedure determines mediation by examining the strength of the indirect relation between trauma exposure and $\mathrm{WM}_{\mathrm{r}}$ through PTSD symptoms. We used the predicted values from the first model, therefore a composite score representing severity of exposure, as our independent variable, PTSD symptoms as the mediator, and WM accuracy as the dependent variabie. The direct effect, between exposure and WM was estimated at .34

Table 4. Correlations between WM performance and other variables.

\begin{tabular}{lccc}
\hline & Whaccuracy & Severity of abuse & Generai life stress \\
\hline Severity of abuse & $-.16^{*}$ & & \\
& $n=228$ & & \\
Generaj tife stress & $-.27^{* * *}$ & $35^{* *}$ & \\
& $n=227$ & $n=230$ & $.40^{* *}$ \\
PTSD & -.08 & $52^{* *}$ & $n=145$ \\
\hline
\end{tabular}

Notes $R$ values of correlations between the different variables, with valid $n$ for each. Values remained similar when controtling for age (WM and severity, $r=-.13, p=.06$, general life stress $r=-0.22 p<.01$ and PJ\$D $r=-.09, p=.27$ ). * Signifiçant at $p<, 05$.

* Significant at $p<.01$. 
(95\% $\mathrm{Cl}[.18, .49])$. The estimated magnitude of the indirecl relation, between exposure and WM through PTSD, was small $(-.02,95 \% \mathrm{CI}[-.09, .04])$ and the $\mathrm{CI}$ included 0 , suggesting that the relationship between exposure and WM function was not mediated by PTSD symptoms. Moreover, though not significant, the direct relationship between PTSD and WM was actually positive, in contrast to the negative relationship between stress exposure and WM. An alternative method for testing mediation, the Sobel test, also confirms that the relationship between exposure and WM function is not mediated by PTSD symptoms, $z^{\prime}=0.15, p=.88$.

\section{Discussion}

We examined the possible cognitive correlates of exposure to one PTE: sexual abuse. We found that women reporting experiences of sexual abuse generally showed lower WM performance compared to non-exposed women. Moreover, WM function was more generally systematically negatively related to reports of stressful life experiences. Our findings, therefore, confirm the existence of a link, of moderate size, between trauma/stress exposure and one importani cognitive function: WM. Importantly, our results indicate that this link is not necessarily mediated by PSTD symplons. This suggests that trauma exposure per se can be associated with cognitive conelates, independently of psychopathological symptoms following PTE.

Our studies are correlational, necessarily, since it is impossible to randomly assign participants to either a trauma-exposed or control group. We cannot, therefore, conclude that trauma exposure causes WM deficits. Nevertheless, there are potential cognitive and physiological mechanisms to support an impact of trauma or stress on WM. Cognitively, the experience of emotional events is associated with intrusive thoughts and rumination; trauma can be associated with the activation of irrelevant semantic contents generally (Falsetti, Monnier, Davis, \& Resnick, 2002). According to this account, trauma would be associated with increased task-irreievant thoughts that would take up WM capacity, leading to decreased accuracy or longer reaction times on WM tasks. This is consistent with experimental studies exposing participants to emotional event in the laboratory. Curci et al. $(2013,2015)$ observed that such exposure altered performance on a WM task, and that these emotion-related alterations were largely related to unintended thoughts linked to the emotional event.

Rumination or unintended thoughts, therefore, represents one possible mechanism to account for the link berween trauma exposure and WM function. Studies have shown that most individuals experience unintended thoughts about negative life experiences, often many years after their occurrence (Lehman, Wortman, \& Williams, 1987; Tait \& Silver, 1989). These emotional thoughts may be prioritised, given their significance, and mobilise the allocation of execulive resources, consistent with Pessoass model of emotion-cognition interactions. This suggests that the tendency to ruminate may be an important variable moderating the link between exposure to trauma and WM function. Studies have shown that individuals who ruminate may have particular difficulties inhibiting irrelevant negative contents from WM, leading to more task interference (Joormann \& Gotlib, 2008). This may be even more characteristic of brooding, a type of rumination that involves a passive comparison of one's current situation to unachieved goals (Bernblum \& Mor, 2010). In that study, WM updating was examined in particular. Whereas all participants 
showed a tendency to update negative stimuli more readily, consistent with the attentional prioritisation of emotional contents, brooders showed interference from the mere presence of negative stimuli, even when these were not task relevant. In the context of our study, this suggests that participants with a tendency to ruminate or brood may be especially likely to have task-irrelevant trauma-related thoughts which would interfere with WM performance. Such individual differences could be measured in future studies.

Concerning the link between inhibition of task-irrelevant thoughts and WM function, it is worth noting that the relation should be considered bidirectionally. One experimental study has shown that induced emotional events had a greater impact on task performance of low WM individuals, compared to high WM capacity individuals (Curci et al., 2013). Individuals lower in executive function may be less able to inhibit task-irrelevant thoughts, especially if these are emotional. Indeed, that study showed that low WM individuals reported more rumination following, and up to 24 hours after experiencing the emotional events. The involvement of executive processes can reduce the impact of task-irrelevant emotional distractors (Cohen, Henik, \& Mor, 2011). In a modified version of the attentional network task, emotional cues impacted performance only in congruent trials (when distracters and targets evoked the same response). These trials do not require the involvement of executive processes as much as incongruent trials where distracters lead to a response that must be inhibited. In these incongruent, more difficult trials, the impact of emotional task-irrelevant cues was reduced, showing that involving executive processes attenuates the impact of task-irrelevant emotions. In another study (Cohen et al., $201 \mathrm{l}$ ), it was shown that this effect is particularly pronounced for individuals who tend to use reappraisal as an emotion regulating strategy. This is consislent with the idea of an important link between controlled executive processes and the impact of task-irrelevant emotional stimuli on cognitive performance. Concerning the link between trauma exposure and WM function, both individual differences in executive function and emotion regulation may be important moderators to consider. Specifically, high executive abilities or high WM capacity may act as a protective factor attenuating the link between task-irrelevant emotional thoughts and cognitive performance.

Whereas the reviewed studies provide important suggestions concerning possible cognitive mechanisms underlying the relation between tramma exposure and WM function, it is also possible to envisage physiological mechanisms. A study by Evans and Schamberg (2009) suggests that the link between chronic stress and WM function is mediated by allostatic load (in this case including resting blood pressure, overnight cortisol and catecholamines, and body mass index). In that study they observed a negative correlation between the proportion of childhood spent in poverty (0-13 years) and performance on a WM task, which disappeared when allostatic load was entered as a mediator in the regression equation. Moreover, stress induces the release of hormones such as cortisol which have an impact on neurocognitive function (de Quervain, Aerni, Schelling, \& Roozendaal, 2009), in particular activity of the dorsolateral prefrontal cortex, a structure that is importantly implicated in WM (Curtis \& D'Esposito, 2003). Whereas more research is needed to identify the causal chain, there is a possible neurophysiological pathway between stress/trauma exposure and WM, importantly involving the dorsolateral prefrontal cortex.

Whereas there are possible mechanisms to support the view that trauna exposure affects WM, the reverse relation is also possible. As highlighted previously, our study is 
correlational in nature and hence we cannot draw conclusions concerning the direction of the link. In the PTSD literature, lower cognitive abilities (IQ) have been shown to predate trauma exposure (Breslau, Lucia, \& Alvarado, 2006). Though it is uncomfortable to conceive, and maybe implatsible, our data do not allow us to rule out the theoretical possibility that pre-existing differences in WM abilities could predispose individuals to become victins of sexual abuse. Some prospective studies have shown that IQ can serve as a protective factor against both exposure to PTEs (Breslau et al., 2006) as well as against the development of PTSD symptoms following tratumatic exposure (Gilbertson et al., 2006). Generally, studies also provide evidence that lower IQ is a risk factor for PTSD (Gale et al., 2008). WM is highly correlated with general cognitive functioning including IQ (Qureshi et al., 2011). It is possible that our results highlight one facet of this general link between cognitive functioning and trauma. However, we do not know of any data suggesting a link between IQ and the likelihood of being the victim of sexual abuse.

Another, maybe more plausible account of the inverse causal path (from WM function to increased trauma exposure) is that pre-existing cognitive differences may lead to differences in self-reports of negative experiences. Individuals with lower WM capacity may be more likely to report negative experiences, including experiences of sexual abuse, than individuals with higher WM capacity: Though there is no direct evidence to support this, future studies will be needed to rule out this possibility.

Our investigation presents a number of limitations. Because we focused on trauma exposure, few of our participants exhibited clinically significant levels of PTSD symptoms. Moreover, half of the participants reaching the criterion for PTSD came from one of the four studies, which used a very brief self-report measure of PTSD symptoms. Thus results concerning the comparisons between PTSD and non-PTSD groups must be interpreted with caution. Moreover, PTSD was assessed mostly with self-report questionnaires; only Study 4 included an exhaustive clinical assessment of PTSD (using the CAPS). Another important limitation is that we did not measure when the abuse last occurred, hence we do not know the time that has elapsed since the events. This may be a crucial variable moderating the link between exposure and WM function. It could be expected that the correlation may be stronger when events are more recent. This will need to be assessed directly and considered in future studies. Finally, as mentioned, we cannot conclude that exposure to trauma is causally linked to lower WM function, as our study is correlational and we did not have a pre-trauma measure of WM function. Prospective studies will be necessary to further investigate this link.

Overall, these data have provided important new insights concerning the relation between trauma and cognitive function. Results establish a clear link between WM function and exposule to a PTE. This is important to consider when working with different populations that have been exposed to potentially traumatic experiences or stressful life circumstances. Using a novel analytic strategy, recommended to solve the many problems associated with null hypothesis testing, our results show that this effect is of moderate size. Obviously these results will need to be replicated and confirmed using multiple methodologies and data analytic strategies. Importantly, longitudinal studies should be conducted to determine the direction of this relationship. Our results also clearly show that this relationship between trauma and WM is not mediated by PTSD symptoms. This does not mean that there are no WM deficits specifically associated with PTSD (and indeed 
this has been shown to be the case, see Qureshi et al., 2011), but it does mean that trauma exposure can be associated with altered WM function even in the absence of PSTD symptoms.

\section{Note}

I. In Study 1, we used IES score as our measure of PTSD symptoms.

\section{Disclosure statement}

No potential conflict of interest was reported by the atthors.

\section{Funding}

l'his research was finded by grants awarded to the first author by the Social Scjerces and Humanities Research Council of Canada (SSHRC) [grant number 430-2014-0818] and the Fonds de Recherche en Santé du Québec (FRSQ programme Cherchetu-Boursier).

\section{References}

Bernblutn, R., \& Mor, N. (2010). Rumination and emotion-related biases in refreshing information. Enotion, 10(3), 423-432. doi:10.1037/a0018427

Blanchard, E. B., Jones-Alexander, J., Buckley, T. C., \& Forneris, C. A. (1996). Psychometric properties of the P'ISD Checklist (PCL). Behaviour Research and Therapy, 34(8), 669-673.

Bomyea, J., Risbrough, V., \& Lang, A. J. (2012), A consideration of select pre-trauma factors as key vulnerabilities in PTSD. Clinical Psychology Review, 32(7), 630-641. doi:10.1016/j.cpr.2012.06. 008

Brestau, N. (2009). The epidemiology of trauma, PTSD, and other posttrauma disorders. Trauma, Violence, $\&$ Abuse, 10(3), 198-210. doi:10.117/1524838009334448

Breslau, N., Lucia, V. C, \& Alvarado, G. F. (2006). Intcligence and other predisposing factors in exposure to trauma and posttraumatic stress disordec. Archives of General Psychiatry, 63(11), $1238-1245$.

Brunet, A., St-Hilaire, A. Jehcl, L, \& King, S. (2003). Validation of a French version of the impact of ovent scale-revised. Canadian Journal of Psychiatry, 48(1), 56-61.

Clark, C. R., McFarlane, A. C. Morris, P., Weber, D. L., Sonkkilla, C., Shaw, M., .. Egan, G. F. (2003). Cerebral function in posttraumatic stress disorder during verbal working memory updating: A positron emission tomograply study. Biological Psychiatry. doi:10.1016/S0002-3223(03) $01505-6$

Cohen, N., Herik, A., \& Mor, N. (2011). Can emotion modulate attention? Evidence for reciprocal links in the attentional network test. Experimemal Psychology, 58(3), 171-179. doi: 10.1027/1618$3169 / 2000083$

Cumming, G. (2014). The new statistics: Why and how. Psychologicai Science, 25(1), 7-29. doi:10. $1177 / 0956797613504966$

Curcti, A., Lanciano, T., Soleti, E., \& Rind, B. (2013). Negative emotional experiences arouse rumination and affect working memory capacity. Emotion, 13(5), 867-880. doi:10.1037/a0032492

Curci, A., Soleti, E., Lanciano, T., Doria, V., \& Rimé, B. (2015). Balancing enotional processing with ongoing cognitive activity: The effects of task modality on intrusions and rumination. Frontiers in Psychology, 6, 1-14. doi:10.3389/fpsyg.2015.01275

Curtis, C. E., \& D'Esposito, M. (2003). Persistent activity in the prefrontal cortex during working memory. Trends in Cognitive Sciences, $7(9), 415-423$. 
Engle, R. W., Tulzolski, S. W., Laughiin, J. E., \& Conway, A. R. (1999). Working memory, shortterm menory, and general fluid istelligence: A latent-variable approach. Joumat of Experimental Psychology: General, 128(3), 309-331. doi:doi.org/10.1037/0096-3445.128.3.309

Evans, G. W. \& Schamberg, M. A. (2009). Clildhood poverty, chronic stress, and adult working memory. PNAS Proceedings of the National Academy of Sciences of the United States of America, 106(16), 6545-6549. doi:10.1073/pnas.081 1910106

Falsetti, S. A, Monnier, J., Dayis, J. L., \& Resnick, H. S. (2002). Intrusive thoughts in posttraumatic stress disorder. Joumal of Cognitive Psychothempy, 16(2), 127 ${ }^{2} 43$.

Gale, C. R., Deary, I. J., Boyle, S. H., Barefoot, I., Morlensen, L. H., \& Batty, G. D. (2008). Cognitive ability in early adulthood and risk of 5 specific psychiatric disorders in middle age: "The Vietnam experience study. A rchives of General Psychiatry, 65(12), 1410-1418. doi:10.1001/archpsyc.65.12. 1410

Galletly, C., Clark, C. R, McFarlane, A. C., \& Weber, D. L. (2001). Working memory in postiratamatic stress disorder: An event-related potential study. Jounal of Traumatic Stress, 14(2), 295-309.

Gilbertson, M. W., Paulus, L. A., Williston, S. K., Gurvits, T. V. Lasko, N. B., Pitman, R. K., \& Orr, S. P. (2006). Neurocognitive function in monozygotic twins discordant for combat exposure: Relationship to posttraumatic stress disorder. Joumal of Abnomal Psychology, 115(3); 484495. doi;10.1037/0021-843x.115.3,484

Gotvemement du Qubec. (2014). Agression sexuelie. Document consult de.

Haycs, A. F. (2012). PROCESS: A versatile computational tool for observed variable mediation, wodcration, and conditional process modelling. Retrieved from htp:/wwwafhayes,com/prblic/ process2012.pdf

Hayes, A. F. (2013). Introduction to mediation, moderation, and conditional process analysis: A regression-based approach. New York, NY: Guilford Press.

Isaac, C. L., Cushway, D., \& Jones, G. V. (2006). Is posttraumatic stress disorder associated with specific deficits in episodic mentory? Clinical Psychology Review, 26(8), 939-955.

Joormatun, J., \& Gotlib, 1. H. (2008). Updating the contents of working memory in depression: Interference from irrelevant negative material. Journal of Abnormal Psychology, 117(1), 182192. doi:10.1037/0021-843X.117.1.182

Kletn, $K_{2}$ \& Boals, A. (2001). "The relationship of hife event stress and working memory capacity. Applied Cognitive Psychology, 15(5), 565-579. doi:10.1002/acp.727

LaGarde, G., Doyon, J., \& Brunet, A. (2010). Memory and executive dysfunctions associated with acute posttaaumatic stress disorder. Psychiatry Research, 177(1-2), 144-149. doi:10.1016/j. psychres.2009.02.002

Lehnan, D. R., Wortman, C. B., \& Williams, A. 1. (1987). Long-term effiects of losing a spouse or child in a motor vehicle crash. Journal of Personality and Social Psychology, 52(1), 218-231. doi:30.1037/0022-3514.52.1.218

Luethi, M., Meier, B., \& Sandi, C. (2008). Stress effects on working memory, explicit nemory, and inplicit memory for neutral and emotional stimuli fin healthy men. Frontiers in Behavioral Neuroscience, 2(5), 5. doi: 10.3389/neuro.08.005.2008

Macklin, M. L., Metzger, L. 1., Litz, B. T., McNally, R. J., Lasko, N. B., Orr, S. P., \& Pitman, R. K. (1998). Lower precombat intelligence is a tisk factor for posttraunatic stress disorder. Journal of Consuting and Clinical Psychology, 66(2), 323-326.

Miles, J. N. V., \& Field, A. P. (2007). Perspectives on significance testing. The Irish Journal of Pychology, 28(1-4), 13-26.

Moores, K. A., Clark, C. R., McFarlane, A. C., Brown, G. C. Puce, A., \& Taylor, D. I. (2008). Abnormal tecruitment of working memory updating networks during maintenance of trauma-neutral information in post-traumatic stress disorder. Psychiatry Research: Neuroinaging, 163(2), 156-170. doi:10.1016/j.pscychresns.2007,08.011

Morey, R. A., Dolcos, F., Petty, C. M., Cooper, D. A., Hayes, J. P., LaBar, K. S., \& McCarthy, G. (2009). The role of trauma-retated distractors on neural systems for working memory and emotion processing in posttraumatic stress disorder. Joumal of Psychiatric Research, 43(8), 809-817, doi:10.1016/j.jpsychires.2008.10.014 
Nelson, L, A, Yoash-Gantz, R. E., Pickett, 'I'. C., \& Campbell, T. A. (2009). Relationship between processing speed and executive functioning performance among OEF/OIF veterans: Implications for postdeployment rehabilitation. The Joumal of Head Trama Rehabilitation, 24(1), 32-40. doi:10.1097/HTR 0b013e3181957016

Neylan, T. C., Lenoci, M., Rothlind, J., Metzler, T. J., Schuff, N., An-tao, D., ... Marmar, C. R. (2004). Attention, learning, and memory in posttraumatic stress disorder. Joumal of Traumatic Stress, $17(1), 41-46$.

Pessoa, L. (2005). 'E'o what extent are emotional visual stimuli processed without attention and awareness? Current Opinion in Neurobiology, 15(2), 188-196. doi:10.1016/j,conb,2005.03,002

Pessoa, L. (2009). How do emotion and motivation direct executive control? Trends in Cognitive Sciences, 13(4), I60-166.

Pollack, I., Johnson, L. B., \& Knaff, P. R. (1959). Running memory span. Joumal of Experimental Psychology, 57(3), 137-146. doi:10.1037/h0046137

Prins, A., Ouimette, P., Kimerling, R, Cameron, R. P., Hugelshofer, D. S., Shaw-Hegwer, J., ... Sheikh, J. I. (2003). The primary care PTSD screen (PC-PTSD): Development and operating characteristics. Primary Care Psychiatry, 9, 9-14.

de Quervain, D. J. F., Aerni, A., Schelling, G., \& Roozendaal, B. (2009). Glucocorticoids and the regulation of memory in health and disease. Fronters in Neuroendocrinology, 30(3), 358-370. doit 10.1016/j.yfrne.2009.03.002

Qureshi, S. U., Long, M. E., Bradshaw, M. R., I'yne, J. M., Magruder, K. M., Kimbrell, $\mathrm{i}^{+}$., ... Kunik, M. E. (2011). Does PTSD impair cognition beyond the effect of trama? The Joumal of Neuropsychiatry and Clinical Neurosciences, 23(1), 16-28. doi:10.1176/appi.neuropsych.23.1.16

Redick, T. S., Broadway, J. M., Meier, M. E., Kuriałose, P. S., Unswortl, N., Kane, M. J., \& Engle, R. W. (2012). Measuring working memory capacity with automated complex span tasks. European Journal of Psychological Assessment, 28(3), 164-171.

Resnick, H. S., Kilpatrick, D. G., Dansky, B. S., Saunders, B. E:, \& Best, C. L. (1993). Prevalence of civilian Lrauma and posttraumatic stress disorder in a representative national sample of women. Journal of Consulting and Clinical Psychology, 61(6), 984-991. doi:10.1037/0022-006x.61.6.984

Saint-Onge, S. (n.d.). Version française du Clmician Administered PTSD Schedule.

Schoofs, D., Preuss, D., \& Wolf, O. T. (2008). Psychosocial stress induces working menory impairments in an n-back paradigm. Psychoneuroendocrinology, 33(5), 643-653. doi:10.1016/j. psyluelien.2008.02.004

Schweizer, S. \& Dalgleish, T: (2011). Emotional working memory capacity in posttraumatic stress disorder (PTSD). Behowiour Research and Therapy, 49(8), 498-504. doi:10.1016/j,brat,2011.05. 007

Scott, J. C., Matt, G. E., Wrocklage, K. M., Crich, C., Jordan, J., Southwick, S. M., .. Schweinsburg, B. C. (2015). A quantitative meta-analysis of neurocognitive funclioning in posttraumatic stress disorder. Psychological Bulletin, 141(1), 105-140, doi:10,1037/a0038039

Sliwinski, M. J., Smyth, J. M., Hofer, S. M., \& Stawski, R. S. (2006). Intraindividual coupling of daily stress and cogniton. Psychology and Aging, 2I(3), 545-557. doj:10.1037/0882-7974.21.3.545

Stawski, R. S., Sliwinski, M. J., \& Snyth, j. M. (2006). Stress-related cognitive interference predicts cognitive function in old age. Psychology and Aging, 21(3), 535-544, doi-10.1037/0882-7974.21.3. 535

Suliman, S., Mkabile, S. G., Fincham, D. S., Ahmed, R., Stein, D. J., \& Seedat, S. (2009). Cumtlative effect of multiple trauma on symptoms of posttraumatic stress disorder, anxicty, and depression in adolescents. Comprehensive Psychiatry, 50(2), 12 I-127. doi:10.1016/j.comppsych.2008.06.006

'Lait, R., \& Silver, R. C. (1989). Coming to teruns with major negative life events. In J. S. Uleman \& ]. A. Bargl: (Eds.), Unintended thought (pp. 351-382). New York, NY: Guilford Press.

'Tapia, G, Clarys, D., El-Hage, W., \& Isingrini, M. (2007). Les troubles cognitifs dans le post-traumalic stress disorder (P'ISD): Une revue de la litterature, LAmée Psychologique, 107(3), 489.. 523. doi:10.4074/s0003503307003065

Taverniers, J., Van Ruysseveldt, J., Smeets, T., \& von Grumbkow, J. (2010). High-intensity stress elicits robust cortisol incrieases, and impairs working memory and visto-spatial declarative 
memory in special forces candidates: A field experiment. Stress: The Intentional Joumal on the Biology of Stress, 13(4), 324-334. doi:10.3109/10253891003642394

Trafimow, D., \& Marks, M. (2015). Editorial. Basic and Applied Social Psychology, 37(1), 1-2. doi:10.1080/01973533.2015.1012991

Unsworth, N., Heitz, R. P., Schrock, J. C., \& Engle, R. W. (2005). An automated version of the operation span task. Behtavior Research Methods, Instruments and Computers, 37, 498-505.

Vasterling, J. J., Brailey, K., Constans, J. I, \& Sutker, P. B. (1998). Attention and memory dysfunction in posttraumatic stress disorder. Neuropsychology, 12(I), 125-133. doi:10.1037/0894-4105. 12.1.125

Vieillard, $S_{\text {, }}$ \& Bougeant, J. (2005). Performances à tune tâche de mêmoire de travail Sous induction émotionnelle négative : Influence modulatrice de l'ćtat émotionnel sur les processuss exécutifs Effect of an induced negative emotion on working memory task performance: The moderating effect of emotional state on storage and executive processes]. L'année Psychologique, 105(1), 63104. doi: $10.3406 /$ psy.2005.3820

Weber, D. L., Clark, C. R., McFarlane, A. C., Moores, K., Morris, P., \& Egan, G. F. (2005). Abnormal fronlal and partelal activity during working memory updating in post-traumatic stress disorder. Psychiatry Researdh: Neuroimaging, 140(1), 27-44. doi:10.1016/j.pscychresns.2005.07.003 